\title{
El fronting: una \\ perspectiva a partir del ordenamiento jurídico colombiano $^{1}$
}

\section{Fronting: An Overview From Colombian Legal System}

\author{
Tatiana Gaona Corredor ${ }^{2}$
}

\section{RESUMEN}

La legislación colombiana no se ha ocupado de definir el contrato de reaseguro y de la operatividad que conlleva el fronting. Por tanto, se hace indispensable establecer cuáles son sus principales características, tipos y en especial las obligaciones y derechos de las partes que intervienen cuando una operación de este tipo es puesta en ejecución.

Palabras clave: reaseguro, fronting, corredor de reaseguros, reasegurador, cesión del riesgo.

\section{ABSTRACT}

Colombian law has not defined the reinsurance contract and the fronting operation involved. Therefore, it is essential to establishing what are its main

1 Fecha de recepción: 17 de agosto de 2015. Fecha de aceptación: 14 de diciembre de 2015 . Para citar el artículo: Gaona, T "El fronting: una perspectiva a partir del ordenamiento jurídico colombiano". Revist@ E-Mercatoria, vol. 14, №2, julio - diciembre, 2015. DOI: https://doi.org/10.18601/16923960.v14n2.04

2 Coordinadora Jurídica en QBE SEGUROS S.A. y Asistente de Investigación del Departamento de Derecho Comercial de la Universidad Externado de Colombia. Abogada de la Universidad Externado de Colombia y Especialista en Derecho Comercial de la misma institución.Contacto: gaona_corredor@hotmail.com mailto:jnunez@pucesa.edu.ec 
characteristics, types and especially the rights and obligations of the parties involved when this operation is implemented.

Key words: reinsurance, fronting, reinsurance broker, reinsurer, transfer of risk.

\section{INTRODUCCIÓN}

Si bien el contrato de reaseguro es de vieja data, y la doctrina que se ocupa del análisis de la operación desde el punto de vista técnico, financiero y jurídico es abundante ${ }_{i}$ la incipiente regulación normativa en Colombia al respecto, ha traído como consecuencia que la implementación de las buenas prácticas que a nivel internacional son comunes sean de escaza aplicación en nuestro país.

Ahondar en este tema resulta de trascendencia cuando los aseguradores locales y los doctrinantes a falta de regulación normativa exhaustiva, poseen interrogantes que traspasan la órbita del tecnicismo del contrato. El alcance y el impacto de la estipulación de cláusulas que desnaturalizan de suyo la concepción tradicional del contrato de reaseguro, implican dificultades interpretativas que recaen directamente en las partes vinculantes en el contrato de seguro inicial.

Para comenzar, es preciso señalar que la legislación colombiana no se ha ocupado de definir el contrato de reaseguro y mucho menos de la operativa que conlleva el fronting. El Código de Comercio abarca esta temática únicamente en los artículos 1134 a 1136, 1080 y 1744, en los cuales hace referencia a las obligaciones que el reasegurador adquiere en virtud del contrato de reaseguro, el carácter supletivo de dichas normas y la inoponibilidad del contrato de reaseguro respecto a las obligaciones que ostenta el asegurador directo respecto a la parte asegurada. Sobre este tema volveremos en detalle en el primer capítulo de este escrito.

El Estatuto Orgánico del Sistema Financiero -en adelante EOSF-, en el Capítulo XI de la Parte Primera y en los artículos 183 y siguientes, regula la actividad aseguradora y reaseguradora en el país. Respecto a la cesión y aceptación de reaseguros, la Superintendencia Financiera de Colombia -en adelante SFC-, en ejercicio de sus funciones debe velar porque los principios de seguridad, certeza y oportunidad se cumplan en las condiciones impuestas para las operaciones de cesión y aceptación de reaseguro que efectúen las entidades reaseguradoras.

Adicionalmente, la Parte II Título IV Capítulo II de la Circular Básica Jurídica, consagra lo que representa la génesis del reaseguro, al obligar a las aseguradoras que pretenden obtener la autorización para un ramo específico para que presenten la nota técnica respectiva con el sustento de la tasa pura de riesgo, los porcentajes por concepto de gastos de administración, comisión de intermediación y utilidad esperada por la aseguradora. En el evento que el porcentaje de retención de riesgo resulte inferior al $20 \%$, el componente de 
tasa pura de riesgo de la nota técnica puede ser aquel que establezca el reasegurador, en el evento que el porcentaje sea mayor, dicho componente debe ser sustentado por la entidad aseguradora. El cumplimiento de dicha obligación es permanente, sin perjuicio de que las politicas del reaseguro varien una vez aprobado el ramo.

Respecto a los porcentajes de retención sobre los riesgos asumidos por las entidades aseguradoras, el límite máximo de retención, está consagrado en el artículo 2.31.1.3.1 del Decreto 2550 de 2010 cuyo texto establece que las entidades aseguradoras y reaseguradoras no podrán asumir en un sólo riesgo una retención neta que exceda del diez por ciento (10\%) de su patrimonio técnico correspondiente al trimestre inmediatamente anterior a aquel en el cual se efectúe la operación. Para la cuantificación del riesgo, se realiza la sumatoria de todos los valores asegurados y reasegurados de un mismo evento.

Sin perjuicio de lo anterior, la legislación no establece restricciones respecto al porcentaje que las aseguradoras están autorizadas a ceder a las reaseguradoras. Dicho porcentaje puede oscilar entre el $0 \%$ y el $100 \%$ en razón de diversos factores, tales como: a) la naturaleza del contrato de seguro celebrado (de grandes envergaduras, como las pólizas globales financieras), b) el apetito de riesgo de la aseguradora (directrices de la compañía, sugieren la existencia de un reaseguro mayor) o c) por política legislativa que en razón a la tipología del seguro, la aseguradora está obligada a asumir los riesgos derivados del mismo con una compañía reaseguradora. ${ }^{3}$

En ese sentido, si la compañía aseguradora, pretende ceder a una compañía reaseguradora la totalidad del riesgo asumido o asumir para sí, una ínfima parte del mismo, la asunción del riesgo radicaría en cabeza del reasegurador y no del asegurador-cedente, quien asume una posición aparente frente al asegurado y desaparece su rol de asegurador directo. Esta operación es lo que se denomina fronting.

El fronting en su sentido puro, se presenta cuando el contrato se seguro se celebra entre quien asume el reaseguro y el asegurado (cliente). El asegurador interviene en la operación para cumplir con obligaciones documentales (expedición de la póliza por ejemplo) emanadas de la ley y no porque la esencia del contrato lo obligue a ello, ni siquiera por ser quien celebra el contrato.

3 El artículo 1 del Decreto 2272 de 1993, consagra que:

En la operación técnica del seguro y del reaseguro de terremoto, las entidades aseguradoras deberán observar que la responsabilidad neta proveniente de la integridad de sus contratos de seguros y de reaseguros, calculada en función de una pérdida máxima probable equivalente, cuando menos, al quince por ciento (15\%) de los valores asegurados y/o reasegurados, no podrá exceder por cada una de las zonas sísmicas, del diez por ciento (10\%) de su patrimonio técnico correspondiente al trimestre inmediatamente anterior a aquel en el cual se efectuó la operación. Se entiende por responsabilidad neta aquella que queda a cargo de la compañía, una vez deducida la correspondiente a sus coaseguradores y reaseguradores en contratos proporcionales. 
El propósito de este trabajo, es presentar una visión general del fronting: su definición, principales características, clasificación y en especial las obligaciones y derechos del asegurador, reasegurador, asegurado y corredor de reaseguros cuando una operación de este tipo es puesta en ejecución.

En la segunda sección, se expondrán las principales cláusulas que son de usanza en los contratos de fronting, cuya naturaleza influye directamente en los derechos adquiridos por los asegurados en el contrato de seguro que dio origen al contrato de fronting. Por tanto, se estudiará su génesis y la sanción jurídica que el ordenamiento jurídico colombiano les atribuye.

\section{LINEAMIENTOS GENERALES DEL FRONTING}

\subsection{UnA APROXIMACIÓN AL CONCEPTO DE FRONTING}

Pese a que el contrato de reaseguro y de fronting no están definidos por la legislación colombiana, la doctrina se ha ocupado de estos aspectos conceptuales. El Doctor Carlos Ignacio Jaramillo, define en sentido lato el contrato de reaseguro como aquel en virtud del cual un reasegurador, a cambio de una prima reconocida por el asegurador directo (cedente), se compromete a indemnizar, con arreglo a la modalidad convenida, las pérdidas derivadas exclusivamente del ejercicio de su objeto social: "asunción de riesgos"

En términos similares, el doctor Efrén Ossa, concibe al contrato de reaseguro, como un sistema de distribución vertical del riesgo, rectamente por el asegurador con el objeto de nivelar su eventual responsabilidad frente al asegurado en guarda del presupuesto de la uniformidad cuantitativa que es uno de los principios que gobierna la operación racional del seguro, el reaseguro produce el efecto de atomización, pulverización o nivelación de riesgos. ${ }^{5}$

Ahora bien, respecto al fronting, Carlos Ignacio Jaramillo, lo define como: "la operación que realizan asegurador directo y reasegurador directo y reasegurador, con miras a ceder $y$, por consiguiente a aceptar, en su orden la mayor proporción y, preferiblemente, la totalidad de las consecuencias desfavorables emergentes de la materialización de uno o varios riesgos que, con antelación o en forma concomitante han sido "asumidos" contractualmente por aquel en sentido figurativo" ${ }^{\prime \prime}$.

Maria Isabel Candelario Macías, considera que el fronting describe una forma especializada de reaseguro o garantía empleada con frecuencia en el

4 IGNACIO JARAMILLO, Carlos Ignacio. El Contrato de Seguro. Bogotá: Pontificia Universidad Javeriana, Temis, 2013, V vol. p. 297.

5 Ibíd., p. 299.

6 IGNACIO JARAMILLO, Carlos Ignacio. Distorsión Funcional del Contrato de Reaseguro Tradicional. Bogotá: Pontificia Universidad Javeriana, 1999. p. 352. 
mercado internacional del seguro, mediante la cual el asegurador-la compañía que afronta- publica políticas a petición de uno o más aseguradores con la intención de transferir el riesgo entero a otros sujetos, a través de un acuerdo de reaseguro u otra garantía o cobertura ${ }^{7}$.

Desde el punto de vista técnico, el fronting representa para el aseguradorcedente, aumentar o mantener los márgenes de solvencia y capacidad financiera. Si la cesión del riesgo se realiza en su totalidad a una compañía reaseguradora, esta es a quien se le atribuyen las prestaciones estipuladas en el contrato de reaseguro y el pago de los siniestros ocurridos -sin perjuicio de los riesgos inherentes de la operación-, por lo cual, la compañía aseguradora-cedente no tendrá que soportar directamente el pago de las indemnizaciones que se generen con ocasión de las reclamaciones presentadas por los asegurados, so pena que sea está quien, para efectos operativos pague las indemnizaciones al asegurador pero los fondos provengan del reasegurador.

Desde el punto de vista financiero, la situación es distinta. El reasegurador quien ve justificada la celebración de este tipo de contratos con la retribución de su labor en una remuneración que está abastecida por la prima que sufraga el tomador del seguro inicial, también es un factor de alto riesgo para el asegurador-cedente quien sin perjuicio de que el reasegurador no le retribuya el monto que este tuvo que pagar al asegurado, al asegurador-cedente no lo queda más remedio que perseguir el cumplimiento de lo estipulado en el contrato de fronting sin tener excepción válida frente al asegurado, a quien se le debe el pago de la indemnización, como prestación arquetípica del contrato de seguro en cabeza del asegurador.

Lo anterior determina un riesgo de solvencia financiera para las compañias de seguros, quienes de una parte deben cumplir con las obligaciones a su cargo del contrato de seguro y a su vez pagarle al reasegurador la comisión del contrato de reaseguro con el alea que al momento de cobrarles la proporción que a ellas corresponde, las reaseguradoras no respondan.

Respecto al ámbito comercial y gerencial, la justificación de la celebración de contratos de reaseguro fronting, es palmaria. Cuando ocurre la cesión total del riesgo asumido por parte de la aseguradora a una compañía reaseguradora, la primera tiene la posibilidad de ampliar su portafolio de productos y lograr un mayor posicionamiento en el mercado asegurador.

Desde esta óptica, el riesgo se materializa en el evento en que la compañía reaseguradora no cumpla con las obligaciones emanadas del contrato de reaseguro fronting y la compañía aseguradora-cedente como garante frente al asegurado se vea obligado al pago de las indemnizaciones a que haya lugar, sin haber recibido los dineros provenientes de la prima para constituir la reserva ventajas. En: Foro de Derecho Mercantil: Revista Internacional, 2005, no. 8, p.5. 
respectiva ${ }^{8}$. El riesgo reputacional de la compañia aseguradora, es el factor de mayor embergadura en este aspecto.

Bajo el supuesto de que una de las funciones del reaseguro es aumentar "la capacidad interna de aceptación del asegurador directo", 9 a nuestro juicio el fronting es una operación mediante la cual el asegurador cede a un reasegurador la totalidad o casi la totalidad del riesgo inicialmente asumido. Se crea entonces, lo que los ingleses denominan, un "seguro de fachada", expresión que se utiliza para designar a la entidad aseguradora-cedente que asume un riesgo pero transfiere la cobertura integra o gran parte de ella a otros reaseguradores ${ }^{10}$.

La operación, se puede ilustrar a través de la siguiente gráfica:
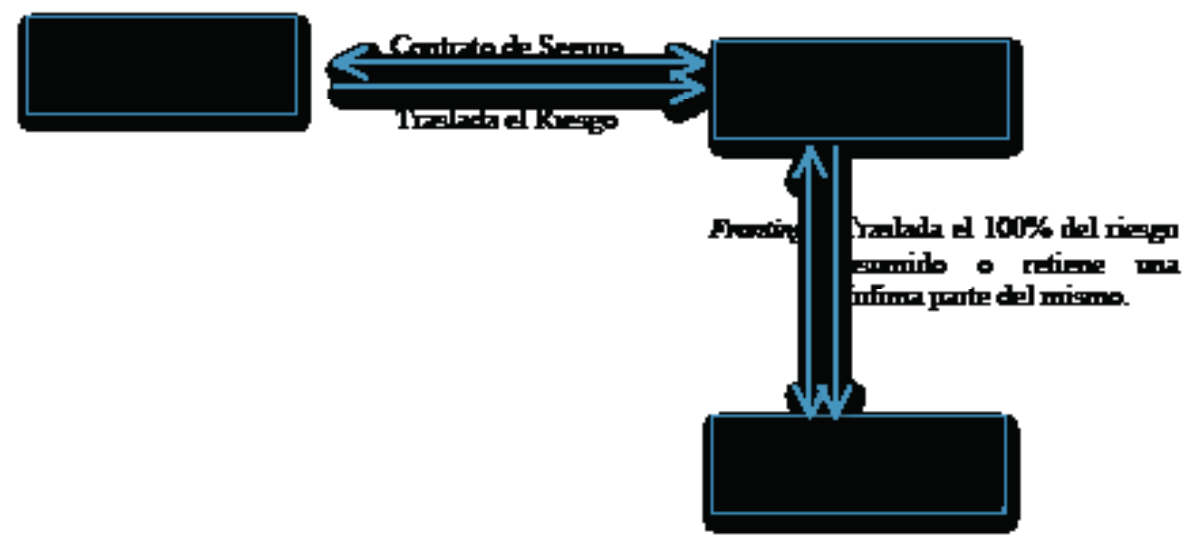

Por mandato legal, ${ }^{11}$ para que una compañía de seguros constituida en el exterior opere legalmente en Colombia, debe constituir una oficina de representación en nuestro país. Sin embargo, con la operatividad del fronting, ello no es necesario. La compañía aseguradora-cedente expide la póliza y en consecuencia asume la totalidad del riesgo frente al tomador del seguro, a quien no le interesa si esta a su vez traslada el riesgo a otra compañía constituida en el exterior, que no esta autorizada para realizar operaciones de seguro en Colombia. ${ }^{12}$

8 Vale la pena aclarar que dicho suceso acontece únicamente en los contratos de reaseguro, en los cuales se pactó la cláusula de pago simultáneo y en virtud de la cual, existe una grave injerencia del reasegurador en el pago de la indemnización a favor del asegurado del contrato de seguro primigenio.

9 IGNACIO JARAMILLO, Carlos Ignacio. El Contrato de Seguro, Bogotá, Pontificia Universidad Javeriana, Editoral Temis, Tomo V, 2013, p. 301.

10 MATRÁN Julio Caselo y GUARDIOLA Antonio. Diccionario Mapfre de Seguros, Madrid, Fundación Mapfre, 2008, p. 211.

11 Circular Básica Jurídica, Capítulo V, Titulo I.

12 Al respecto, el doctor José Maria Muñoz Paredes, en su obra "El Coaseguro", manifiesta que la razón fundamental por la que se acude al fronting es "eludir las necesarias autorizaciones y controles administrativos para el ejercicio del seguro directo en un país". 
A diferencia de la legislación colombiana, en la cual no se establece ningún tipo de regulación específica para este tipo de operaciones, otras legislaciones de países latinoamericanos, se han ocupado de regular los aspectos básicos de las operaciones de reaseguro fronting. A manera de ejemplo, la Ley General de Seguros, Reaseguros y Fianzas No. 733, del 15 de Julio del 2010, de Nicaragua, en su artículo 3 define al fronting como aquella "operación por la cual se designa a la entidad aseguradora que asume un riesgo, pero transfiere realmente su cobertura íntegra o gran parte de ella a otros aseguradores o reaseguradores extranjeros". En el mismo cuerpo normativo, el artículo 104, consagra que en el evento que una sociedad de seguro desee realizar una operación de fronting, deberá presentar dentro de los treinta (30) días posteriores a la emisión del fronting, todos los documentos que la superintendencia encargada de vigilar estas operaciones en dicho país, exija al respecto.

\subsection{Clasificación del fronting (Una Clasificación meramente ACADÉMICA)}

De acuerdo con lo expuesto, el fronting se configura en la totalidad de los casos en los cuales el asegurador cede la mayor parte del riesgo previamente asumido o el $100 \%$ del mismo. No obstante, para un sector de la doctrina existen dos tipos de fronting: fronting real y fronting falso.

El criterio determinante para su clasificación depende de la oportunidad que tenga el asegurado de escoger al reasegurador. Waldo Sobrino, considera que el fronting real se perfecciona en aquellos casos donde el asegurado es quien pacta las condiciones de cobertura y las cláusulas del seguro con la reaseguradora (líder), por lo que para este autor, cualquier otro tipo de operación no será de esta naturaleza' ${ }^{13}$. El fronting falso, es decir, cuando no hay fronting, se produce cuando la reaseguradora es seleccionada por la aseguradora-cedente y no por el asegurado. Es decir, existe un seguro normal y tradicional, en virtud del cual la compañía de seguros tiene absolutamente todas las responsabilidades legales derivadas de la ley, sin ningún tipo de limitación o restricción.

María Isabel Cancino, adiciona a la clasificación presentada por Sobrino, que en el fronting falso se presenta un seguro normal y tradicional, en el que la aseguradora-cedente tiene que asumir todas las responsabilidades legales frente a la empresa asegurada, sin ningún tipo de limitaciones, dado que la elección de ceder la totalidad del riesgo y la determinación de las reaseguradoras son decisiones empresariales adoptadas en forma unilateral por la compañía de seguros. ${ }^{14}$

13 SOBRINO Waldo. Fronting: un gran peligro para la mayoría de las empresas aseguradas latinoamericanas. Revista Latinoamericana de Seguros, Número 23, Octubre 2005, p. 187.

14 CANDELARIO MACIAS Maria Isabel. Apuntes sobre el "fronting": inconvenientes y 
Consideramos que está clasificación de fronting, tiene efectos meramente académicos. Su utilidad puede representar mayor claridad en el entendimiento de la operación, sin embargo, en la práctica los efectos de la operación se producen sin consideración a los parámetros señalados por los doctrinantes mencionados. Si el asegurador tiene injerencia en la escogencia del reasegurador es indiferente respecto a la responsabilidad que ostenta el aseguradorcedente, las obligaciones del contrato de seguro se mantienen incólumes y con ello la obligación del asegurador de soportar el detrimento económico que puede representar que el reasegurador no conmine las obligaciones del contrato de reaseguro celebrado con ocasión del contrato de seguro original.

Para este efecto, coincidimos con Rubén S. Stiglitz ${ }^{15}$, quien manifiesta que el fronting es una operación económica/jurídica en que el asegurador directo ofrece a un reasegurador su "fachada" (fronting), su "apariencia", su "máscara" y le cede la totalidad, o una calificada proporción de uno o más riesgos que, antes o concomitantemente, ya ha asumido.

En suma, las definiciones que la doctrina ha plasmado, son realizadas en consideración a la intervención del asegurado en el contrato de reaseguro, que para la operatividad en la que se desarrolla el fronting, repetimos, a nuestro juicio no validez alguna.

\subsection{Obligaciones y deRECHOS DE LAS PARTES EN El FRONTING}

\subsubsection{Asegurador}

La génesis del fronting establece que el asegurador-cedente, no puede ignorar su responsabilidad, aduciendo que su función en la operación es meramente nominativa. De cara al contrato de seguro primigenio, el asegurador-cedente ostenta la calidad de asegurador directo y por tanto es el responsable del cumplimiento de las obligaciones derivadas del mismo. ${ }^{16}$

En virtud del artículo 1080 del Código de Comercio, modificado por el artículo 111 de la Ley 510 de 1999, cuyo texto consagra: "El contrato de reaseguro no varía el contrato de seguro celebrado entre tomador y asegurador, y la oportunidad en el pago de éste, en caso de siniestro, no podrá diferirse a

ventajas. Foro de Derecho Mercantil, Revista Internacional No. 8, Editoral: Legis, JulioSeptiembre 2005, p. 38.

15 STIGLITZ Rubén. Temas de Derecho de Seguros, Bogotá Colombia, Pontificia Universidad Javeriana, Facultad de Ciencias Jurídicas: Grupo Editorial Ibañez, 2010 (Colección Internacional No. 23) P.. 278.

$16 \mathrm{Al}$ respecto, PETER STEINLING, en su obra "Problemigiuridichi in connesione con cosiddettofronting" publicada en la Revista Assicurazioni, Roma, 1972, pág. 6, establece: "Se demuestra así que el beneficiario, aunque medie un contrato de fronting, no puede ser privado de su derecho respecto del asegurador directo. Una cláusula en sentido contrario, consideramos nula". 
pretexto del reaseguro"; el asegurador directo (cedente) no puede evadir las obligaciones propias del contrato de seguro que celebró con el asegurado que está reclamando la indemnización respectiva.

Esta apreciación soslaya el riesgo que asume el asegurador-cedente respecto a la solvencia del reasegurador. Como se ha expresado, no existe excepción válida para que el asegurador-cedente no conmine las obligaciones derivadas del contrato de seguro. En caso de insolvencia del reasegurador o del simple retardo del pago del fronting fee por parte del reasegurador al asegurador-cedente, este último debe asumir completa responsabilidad frente al asegurado, a quien poco le interesa si este posee los fondos para proceder al cumplimiento de su obligación.

En ese sentido, coincidimos con Sergio Barroso de Mello, toda vez que "la responsabilidad contractual del asegurador se mantiene intacta y queda como responsable directo y único por todas las obligaciones que aparezcan en el ámbito contractual del seguro, en relación al asegurado que tenía el interés legítimo, incluyendo las más importantes como el cumplimiento de la garantía, especialmente el pago de las indemnizaciones en el caso de siniestro"17.

De acuerdo al artículo 1134 del Código de Comercio, modificado por el artículo 83 de la Ley 45 de 1990: "En virtud del contrato de reaseguro el reasegurador contrae con el asegurador directo las mismas obligaciones que éste ha contraído con el tomador o asegurado y comparte análoga suerte en el desarrollo del contrato de seguro, salvo que se compruebe la mala fe del asegurador, en cuyo caso el contrato de reaseguro no surtirá efecto alguno"18. Entendemos que el reasegurador asumirá parte de las obligaciones del contrato de seguro, sin embargo, ello no corresponde al escenario del fronting en el cual el asegurador en su calidad de sociedad fronting debe responder ante el asegurado.

Por lo anterior, los términos en cuales se suscriba el contrato de reaseguro fronting ${ }^{19}$ son fundamentales para determinar los plazos, condiciones y montos de los pagos que deben realizarse. Adicionalmente, las partes deben precisar

BARROSO DE MELLO, Sergio. Apuntes sobre el fronting en el reaseguro brasilero, 28 de noviembre de 2010, RIS, Número 33, Bogotá.

18 De acuerdo a lo establecido por Carlos Ignacio Jaramillo, la "comunidad de suerte" que asumen el asegurador directo y el reasegurador es un "postulado en mención solo se extiende a las obligaciones del asegurador directo que fluyen del contrato de seguro (nacientes del siniestro), al mismo tiempo que a las recuperaciones coaligadas a la realización del riesgo asegurado". De lo anterior, se desprende que situaciones como el impago de la prima del asegurado al asegurador directo en el contrato de seguro originario no puede ser una excepción válida del asegurador directo respecto al reasegurador para el pago de la prima derivada del contrato de reaseguro, so pena de pacto en contrario.

19 La Superintendencia Financiera no exige solemnidad alguna para el perfeccionamiento de los contratos de reaseguro, sin embargo, de conformidad a la Circular Básica Jurídica, dichos contratos y las notas de cobertura suscritos por los representantes legales de las entidades aseguradoras cedentes y los apoderadosde los reaseguradores, deberán mantenerse a disposición del ente regulatorio, en las propias entidades aseguradoras y reaseguradoras. 
las condiciones de cada uno de los riesgos cedidos y aceptados y la fecha de formalización de cada operación. Registrada la operación, deben adoptar los mecanismos de control secuencial de las cesiones y las aceptaciones (de reaseguro facultativo) que permitan a las partes contar con elementos que brinden certeza sobre los convenios. ${ }^{20}$

La función de las aseguradoras al seleccionar cuidadosamente las reaseguradoras a quienes pretenden ceder los riesgos asumidos, es fundamental. La junta directiva de cada aseguradora tiene la competencia para establecer la política de retención de riesgos con dos finalidades: a) que garantice la seguridad de la entidad y b) establecer los mecanismos que le permitan conocer mes a mes el valor máximo de exposición por riesgo después de haberse deducido las coberturas del programa de reaseguro. ${ }^{21}$ Establecer una nómina de reaseguradores de reconocida solidez y solvencia le permitirá a la aseguradora minimizar el riesgo de asumir pagos respecto de los cuales no cuenta con las reservas respectivas.

En cuanto a las prohibiciones de las aseguradoras a este respecto, es claro que estas no pueden simular la celebración de contratos de reaseguros cuando no existe transferencia real del riesgo al reasegurador y la retención por parte de la aseguradora es del 100\%. En el evento que la aseguradora celebre este tipo de contratos, esta práctica es considerada como insegura y por lo tanto no autorizada. Su inobservancia acarrea sanciones tanto para el asegurador como para el reasegurador: la imposición de las sanciones previstas en el EOSF y la suspensión del registro del reasegurador en el Registro de Reaseguradores y Corredores de Seguros en el Exterior -en adelante REACOEX-, respectivamente.

\subsection{Reasegurador}

En primer lugar, para que una sociedad reaseguradora ejerza su objeto social en Colombia, debe cumplir con la normatividad para este propósito y registrarse en el REACOEX. Conforme al numeral 4 del artículo 94 del EOSF, el objeto del REACOEX es el de permitir a las entidades de seguros evaluar la calidad de los reaseguradores y corredores de reaseguros del exterior que operen en Colombia a fin de que las aseguradoras sólo contraigan relaciones comerciales con aquellos que cumplan con condiciones mínimas de solvencia, experiencia y profesionalismo, entre otros factores.

De acuerdo al Capítulo III del Título II de la Circular 029 de 2014, la SFC puede autorizar la inscripción en el REACOEX a aquellas entidades reaseguradoras y corredores de reaseguros del exterior que satisfagan los requisitos

20 Circular Básica Jurídica. Circular Externa 008 de 2015. Superintendencia Financiera de Colombia. Parte II, Título IV, Capítulo II, Reglas Generales sobre la operación de seguros.

21 Ibid, p. 230 
enunciados anteriormente. Dicha inscripción faculta a las entidades reaseguradoras del exterior, únicamente para aceptar o ceder en Colombia responsabilidades en reaseguro y a los corredores de reaseguro del exterior para intermediar en el país en la celebración de tales contratos, con las entidades de seguros debidamente constituidas en Colombia.

Sin perjuicio de lo señalado en el numeral 3 del art. 94 del EOSF sobre reaseguradoras del exterior, lo establecido en el párrafo anterior supone que sólo aquellas entidades de reaseguro y corredores de reaseguros del exterior que se encuentren inscritas en el REACOEX tienen autorización para actuar en el mercado colombiano de los reaseguros.

Tal es la importancia de dicho registro, que es considerado como una práctica insegura contratar con reaseguradoras y corredores de seguros en el exterior que no se encuentren inscritos en el REACOEX o cuya inscripción se encuentre suspendida o cancelada por la SFC al momento de la negociación, así como también, contactar intermediarios de reaseguros a través de corredores de reaseguro del exterior no inscritos en el REACOEX o cuya inscripción se encuentre suspendida o cancelada al momento de la negociación.

Es indudable el carácter técnico del contrato de reaseguro, cuyo propósito será en términos generales soportar el patrimonio del asegurador cuando el apetito de riesgo del asegurador aumenta en atención a la demanda del mercado. Sin embargo, se ha discutido que el contrato de seguro se desnaturaliza al ceder el $100 \%$ del riesgo a otra compañía, toda vez que uno de sus elementos esenciales -riesgo asegurable- es trasladado en su totalidad a la compañía reaseguradora y será esta quien se convierta en el asegurador directo.

No obstante, respecto a las operaciones de fronting ejecutadas entre aseguradoras constituidas en Colombia y autorizadas para ejercer su objeto social en nuestro país y reaseguradoras extranjeras, estas no requieren de la autorización y del respectivo registro en el REACOEX. Al respecto, parte de la doctrina ha manifestado que en definitiva el fronting representa la posibilidad para las reaseguradoras de operar en países en los cuales no cuentan con las autorizaciones legales para ello, siempre y cuando la ley de dicho país no lo prohíba expresamente. Así lo ha afirmado Rubén S. Stiglitz, para quien el fronting es utilizado como un instrumento con aptitud para eludir las "autorizaciones necesarias y controles administrativos para el ejercicio del seguro directo en un país" 22 .

A nuestro juicio, debe observarse la normatividad del país en el cual se pretenda ejecutar la operación de fronting. En el evento que la misma prohíba

22 Temas de Derecho de Seguros, Bogotá Colombia, Pontificia Universidad Javeriana, Facultad de Ciencias Jurídicas: Grupo Editorial Ibañez, 2010 (Colección Internacional No. 23) págs. 277-286. La distorsión del Contrato de Reaseguro. El Fronting. Situación en Argentina. (Publicado en la Revista Ibero-Latinoamericana de Seguros No. 23 (Oct. 2005) pp. 173-181. 
expresamente este tipo de operaciones con reaseguradoras que no cumplan con los requisitos de ley, es indiscutible que al proceder de esta manera, las partes tendrán que acarrear con las sanciones correspondientes. Si la ley de dicho país no regula la materia y se pronuncia al respecto, la prohibición no existe y por lo tanto la operación es completamente lícita. Los riesgos propios de la operación deben ser asumidos por la aseguradora-cedente, que bajo este supuesto, no constituirán en ningún evento sanciones de carácter administrativo.

En este aspecto, vale la pena anotar que la posición que ostenta el reasegurador en la operación de fronting lo vincula únicamente en los términos del contrato de reaseguro celebrado con la aseguradora-cedente. La inclusión de cualquier tipo de cláusulas que afecten los derechos adquiridos por la parte asegurada con ocasión del contrato de seguro, son inoponibles al mismo. A manera de ejemplo, no es válida a la luz del ordenamiento colombiano la cláusula de "pago simultaneo", según la cual, la compañía de seguros está habilitada para condicionar el pago de la indemnización al reconocimiento previo de los honorarios que debe el reasegurador a la compañía de seguros en virtud del contrato de reaseguro. Sobre este tema, volveremos en la segunda parte de este escrito.

\subsubsection{Asegurado}

Aunque parezca obvio, es válido mencionar que a pesar de que el contrato de reaseguro guarda su causa en la protección del asegurador que le ha cedido parte del riesgo asumido en virtud del contrato de seguro primigenio, el contrato de seguro y reaseguro son completamente independientes y la operatividad de cada uno de ellos no puede tener ninguna injerencia en el otro.

En lo que respecta a la parte asegurada, la regla es la misma. Sus derechos y obligaciones se mantienen incólumes respecto al contrato de seguro celebrado con el asegurador -cedente, sin consideración de las estipulaciones que puedan pactarse en el contrato de reaseguro fronting para hacer extensiva cargas al asegurado.

La ley colombiana es clara al respecto. El artículo 1135 del Código de Comercio, consagra que el contrato de reaseguro no es un contrato a favor de terceros, por tanto, el asegurado carece de todo tipo de acciones contra el reasegurador, y éste, a su vez, de obligaciones para con aquél.

Bajo ninguna circunstancia, los derechos y obligaciones en cabeza de la parte asegurada pueden ser modificados en virtud del contrato de reaseguro fronting. En algunos eventos, reaseguradores y aseguradores pactan cláusulas que interfieren directamente en las cargas de la parte asegurada del contrato de seguro. En el segundo capítulo se estudiará la sanción jurídica de este tipo de cláusulas y el tratamiento que el ordenamiento colombiano les ha asignado. 


\subsubsection{Corredor de Reaseguros}

De conformidad al Decreto 2555 de 2010, la actividad de intermediación de seguros y reaseguros está reservada a las sociedades corredoras de seguros, a las sociedades corredoras de reaseguros, a las agencias colocadoras de seguros y a los agentes colocadores de pólizas de seguro, de acuerdo con su especialidad. Por tanto, su actividad está sujeta a las disposiciones generales de los Capítulos 1, 2 y 3 del Título 1 del Libro 30 del decreto en mención.

Dentro de este grupo, los únicos llamados a la intermediación de reaseguros son las sociedades corredoras de reaseguros cuyo objeto social le otorga capacidad para ello. No obstante, esto no quiere decir que las aseguradoras cedentes están inhabilitadas para ceder el riesgo a la reaseguradora, sin la intervención de estos intermediarios.

Como es sabido, la labor de los corredores de reaseguros es esencial en el mercado asegurador. Su experticia, conocimiento y la colocación de contratos de reaseguros, hacen indispensable su presencia en este mercado. Así mismo, por la importancia de las labores encomendadas a estos intermediarios, su responsabilidad es mayor, en especial, en el asesoramiento a sus clientes respecto a los negocios que pretenden suscribir.

Respecto al contrato de fronting, sus obligaciones van más allá de la simple promoción del contrato de reaseguro entre la aseguradora y la reaseguradora. En la praxis, muchos de los aseguradores no tienen el conocimiento especializado para realizar el estudio de solvencia al reasegurador o simplemente por política de la compañía, ésta decide trasladar el 100\% de la realización de dicha tarea al reasegurador ${ }^{23}$.

El asesoramiento y la realización de actividades operativas resulta de gran ayuda para la compañía aseguradora quien en virtud del contrato de intermediación de reaseguros, reconoce una comisión al corredor de reaseguros quien tiene el conocimiento para determinar los criterios bajo los cuales debe seleccionar al reasegurador y presentarlo ante su cliente (asegurador directo - cedente).

La responsabilidad de estos intermediarios es indudable, teniendo en cuenta la importancia del reaseguro para mantener el margen de solvencia de las compañias aseguradoras y la embergadura de los riesgos trasladados en operaciones de fronting.

23 Al respecto, Jorge Eduardo Narváez Bonnet, en su investigación "El fronting en el reaseguro y la cláusula cutthrough", pone de presente la importancia de los "Comités de Seguridad", como un mecanismo de evaluación y monitoreo permanente sobre la solvencia de los reaseguradores, porque son grupos de trabajo integrados al interior de los corredores de reaseguro internacionales que se encargan de revisar regularmente la situación de cada uno de los reaseguradores que están autorizados para sus colocaciones. 


\section{CLÁUSULAS FRECUENTES EN LOS CONTRATOS DE FRONTING}

\subsection{Cláusula cut through}

En virtud de la cláusula cut through (cortar camino, atajar) se faculta al asegurado para presentar la reclamación directamente al reasegurador con el fin de obtener el pago de la indemnización.

Dentro de las denominaciones que recibe la cláusula cut tbrough, están las cláusulas de asunción de responsabilidad y cláusula de atajo, ésta última propia de la doctrina española, pues estiman que le permite al asegurado acudir a una vía más expedita para obtener el pago de la indemnización, no en términos de tiempo sino del derecho de crédito que le otorga contra el reasegurador. ${ }^{24}$

Sin duda, esta cláusula estipulada en el contrato de reaseguro, es una estipulación a favor de terceros, que en este evento, corresponde al asegurado, quien no tiene ninguna injerencia en la celebración del contrato de reaseguro. La parte asegurada en el contrato de seguro que dio origen al contrato de reaseguro, es un tercero ajeno a dicho vínculo -cuyas partes únicamente corresponde al asegurador cedente y al reasegurador-.

En la legislación argentina, el artículo 160 de la Ley de Seguros consagra que "el asegurado carece de acción directa contra el reasegurador". Por tanto, se infiere que al asegurado no puede reclamar la indemnización ante el reasegurador, quien no es parte en el contrato de seguro.

En lo que respecta al ordenamiento colombiano, no hace falta un examen exhaustivo de la normatividad para concluir que este tipo de cláusula viola expresamente el artículo 1135 del Código de Comercio, cuyo texto consagra: "El reaseguro no es un contrato a favor de tercero. El asegurado carece, en tal virtud de acción directa contra el reasegurador, y éste de obligaciones para con aquél".

Ahora bien, ¿Cuál es la sanción jurídica que le otorga el ordenamiento jurídico colombiano a la estipulación de estas cláusulas en los contratos de reaseguro? La doctrina no es pacífica al respecto. Algunos sostienen que son cláusulas válidas, toda vez que no son contrarias al orden público y a las buenas costumbres, "por cuanto los sujetos involucrados no requieren una tutela especial porque es más beneficioso acudir al patrimonio del reasegurador" ${ }^{\prime 25}$.

Otro sector de la doctrina, manifiesta que su validez está en entredicho. La posibilidad del asegurador cedente -quien si es parte en el contrato de reaseguro- de ejercer las acciones de recobro directamente al reaseguador, se

24 NÁRVAEZ-BONNET, Jorge Eduardo. El "Fronting" en el reaseguro y la cláusula "Cut Through". En: Revista Iberoamericana de Seguros, 2009, no. 30, p. 158. 
ve cercenada, debido a que el asegurador ya procedió al cobro directo de la indemnización y no habría lugar a ningún tipo desembolso a favor del asegurador cedente.

En nuestro sentir, las cláusulas cut through NO son válidas. Nuestra posición se fundamenta en la transgresión manifiesta de la norma que consagra la prohibición expresa y no en la afectación de los derechos de las partes del contrato de reaseguro, dicho argumento, resulta secundario cuando la norma se ocupa de regular este aspecto contractual del contrato de reaseguro de forma puntual.

Sabemos que, la regulación legislativa respecto del respecto contrato de reaseguro no es exhaustiva. Los problemas que se suscitan a nivel contractual, han sido temas de frecuente discusión a nivel doctrinal justamente por el silencio que el legislador ha predicado al respecto. No obstante, al parecer la intención del legislador sobre este punto fue enfática al regular este aspecto contractual, muestra de ello, es la consagración expresa de la prohibición de la referencia.

Rubén S. Stiglitz, manifiesta que la cláusula cut through importa una clara desnaturalización del contrato de reaseguro pues es aprovechada por los reaseguradores no autorizados a operar en el país del seguro directo, lo que significa que implican un fraude a la ley ya que "bajo la apariencia de un contrato de reaseguro, se oculta un auténtico seguro directo" 26

\subsection{Cláusula de Control de reclamos}

Mediante esta cláusula se supedita el cumplimiento de las obligaciones emanadas del contrato de reaseguro, a la realización de los avisos y al sometimiento de los controles respecto del reasegurador contemplados en el contrato de seguro.

En palabras de Waldo A. R. Sobrino, la cláusula de control de reclamos, es un convenio por el cual la reaseguradora y la compañía de seguros establecen que la liquidación del siniestro y la determinación del pago, va a quedar -en forma exclusiva- en cabeza de la reaseguradora ${ }^{27}$.

A manera de ejemplo, la cláusula de control de reclamos puede estipularse en los siguientes términos: "Es condición precedente a cualquier responsabilidad bajo esta póliza que: a) El reasegurado dé aviso inmediatamente al reasegurador de cualquier pérdida o acontecimiento que pueda generar un reclamo recobrable bajo esto, b) El reasegurado deberá suministrar al reasegurador toda la información disponible con respecto a tales pérdidas o acontecimientos y los reaseguradores tendrán el derecho de contratar con ajustadores/asesores

26 STIGLITZ Rubén. La distorsión del Contrato de Reaseguro. El Fronting. Situación en Argentina. En: Revista Ibero-Latinoamericana de Seguros no. 23, 2005, p. 173.

27 SOBRINO, Waldo A. Fronting: un gran peligro para la mayoría de las empresas aseguradoras latinoamericanas. En: Revista Ibero-Latinoamericana de Seguros, no. 23, 2005, p. 196. 
o investigador y controlar todas las negociaciones, ajustes o acuerdos en conexión con tales pérdidas o acontecimientos".

Con ocasión del proceso arbitral de la Fiduciaria Caldas S.A. contra Seguros Atlas S.A., se discutió la validez de la cláusula de control de reclamos pactada en la Póliza Global de Entidades Financieras que expidió la demanda a favor de Fiduciaria Caldas S.A. en la que fue amparado el riesgo de infidelidad de empleados. La Fiduciaria tuvo una pérdida ocasionada en la defraudación atribuida a algunos de sus funcionarios, por tanto, procedió a formular la reclamación respectiva ante la aseguradora, quien aceptó la responsabilidad y procedió al pago tardío de la indemnización correspondiente aduciendo la cláusula de control de reclamos estipulada en el contrato de reaseguro. Al respecto, el Tribunal de Arbitramento, manifestó ${ }^{28}$ :

"No hay duda que esta cláusula supedita el cumplimiento de obligaciones a cargo del asegurador. Tampoco es cuestionable que el cumplimiento de tales condiciones tiene el propósito de suspender hasta su realización la obligación consistente en pagar el siniestro; tal es el alcance del poder de control de reclamos de "todas las negociaciones, ajuste o acuerdos" que se otorga a un tercero. El tercero, a quien la póliza faculta para decidir la exigencia de pago es el reasegurador, bien que éste actúe directamente o a través de ajustadores, asesores o investigadores. Nada de eso es compatible con la ley y con la estructura del contrato de reaseguro.

(...)

Resulta indudable que la estipulación contractual examinada difiere el pago del siniestro al visto bueno del reasegurador, que es exactamente la conducta proscrita por la ley. En la práctica si la obligación primordial del asegurador pudiese condicionarse a la conducta que el eventual reasegurador adopte, el reasegurador vendría a ser el verdadero asegurador y este último actuaría como un mero agente del primero, lo cual equivaldría a desmantelar el sistema diseñado con tanto detalle por la ley.

(...)

La cláusula de control de reclamos, en tanto condiciona la obligación resarcitoria del asegurador al control ejercido por el eventual reasegurador, pugna con las normas legales de las que se ha hecho mención. Tal pugnicidad constituye causal de nulidad absoluta. Según el Código de Comercio, artículo 889, adolece de nulidad absoluta el negocio jurídico cuando contraría una norma imperativa, salvo que la ley disponga de otra cosa".

En todo caso, esta cláusula proscrita en el contrato de seguro, no tiene los mismos efectos en el contrato de reaseguro. El planteamiento radica en que los

28 Laudo Arbitral en derecho del 8 de noviembre de 1995. Árbitro: José Humberto Botero. Secretario: Jorge Hernán Gil Echeverry. Tomado de la obra: Laudos Arbitrales en Materia de Seguros, Tomo II, Cámara de Comercio-Acoldese-Aida, 2004. 
contratos de seguro y reaseguro a pesar de ser completamente independientes, por disposición legal, ${ }^{29}$ comparten análoga suerte.

Teniendo en cuenta que en el fronting, será el reasegurador quién soporte casi la totalidad del pago de las indemnizaciones a las que haya lugar, resulta claro su interés de mantener el control de las reclamaciones hechas con ocasión del contrato de seguro. Sin embargo, dicha obligación será impuesta al asegurador-cedente, quien es parte en dicho contrato y no a la parte asegurada del contrato de seguro primigenio.

Vale la pena mencionar que constantemente la cláusula de control de reclamos está ligada a la cláusula de cooperación, llamándola en muchos casos, cláusula de cooperación y control de reclamos, como si se tratara de un mismo tipo de cláusula. Este indebido tratamiento conduce a confusiones.

Como lo manifiesta, Juan Achurra Larraín, una cláusula de cooperación de siniestros es la que dispone que la compañía aseguradora-cedente deberá mantener permanentemente informado al reasegurador respecto de los avances y circunstancias de la liquidación y le consultará su opinión en cuanto a las gestiones que estime pertinentes desarrollar, mientras que, la cláusula de control de reclamos, establece que la aseguradora-cedente no podrá preceder sin la autorización del reasegurador al nombramiento de liquidadores asesores, inspectores y/o abogados, debiendo contar con la aprobación previa del reasegurador todas las negociaciones, finiquitos y liquidaciones de la pérdida, quedando facultado el reasegurador para obtener la autorización de peritajes y convenir la pérdida a un solo árbitro ${ }^{30}$.

\subsection{Cláusula de pago simultáneo}

En virtud de esta cláusula (simultaneous payment clause), la aseguradora cedente tiene la facultad de no proceder al pago de la indemnización a favor del asegurado, aduciendo que el reasegurador con quien celebró el contrato de fronting no le ha transferido los fondos con los cuales debe pagar las indemnizaciones respectivas.

En lo que respecta a la validez de estas clausulas en el contrato de seguro, guardamos los argumentos presentados frente a las clausulas expuestas anteriormente. Es indudable, que el ordenamiento jurídico colombiano sanciona

29 Artículo 1134 del Código de Comercio: "En virtud del contrato de reaseguro, el reasegurador contrae con el asegurador directo las mismas obligaciones que éste ba contraído con el tomador o asegurador y comparte análoga suerte en el desarrollo del contrato de seguro".

30 "Las cláusulas de Cooperación y Control en los Contratos de Reaseguro. http://www.aidachile.cl/clp/archivos/2012/01/LAS-CLÁUSULAS-DE-COOPERACIÓN-Y-CONTROLEN-LOS-CONTRATOS-DE-REASEGURO-Juan-Achurra-Larra\%C3\%ADn.pdf. Viernes, 7 de agosto 2015 . 
estas cláusulas con nulidad absoluta por contravenir las normas imperativas que regulan el contrato de seguro.

No obstante lo anterior, para otros autores la sanción jurídica dista de la nulidad absoluta. Waldo A. Sobrino, sostiene que la cláusula de pago simultáneo, es una cláusula abusiva, en razón a que, en virtud de esta la compañía de seguros no se encuentra obligada al pago de ninguna indemnización, hasta tanto, no le haya sido previamente remitido los fondos necesarios por la reaseguradora ${ }^{31}$.

Rubén S. Stiglitz, analiza la operatividad de esta cláusula a la luz del ordenamiento jurídico argentino, concluyendo que la cláusula es ilícita en tanto vulnera los artículos: a) 49 de la Ley de Seguros -en adelante LS- que fija un plazo para el pago de la indemnización, término que sólo es factible de ser modificado a favor del asegurado (art. 158-3 LS), b) art. 50 LS según el cual es nulo el convenio que exonere al asegurador de la responsabilidad por su mora, c) arts. 1 y 61 LS por cuanto la obligación principal a cargo del asegurador no es factible de subordinarse a un previo suministro de fondos de un tercero ajeno al contrato y d) art. 159 LS en tanto establece que si bien el asegurador puede, a su vez, asegurar los riesgos asumidos, "es el único obligado frente al tomador del seguro". Adicionalmente, sostiene que la cláusula es también abusiva en tanto provoca un desequilibrio significativo entre los derechos de las partes al ampliar inequitativamente los del asegurador en detrimento de los del asegurado, desnaturalizando la relación obligacional ${ }^{32}$.

En la sentencia proferida con ocasión del Proceso de la Libertad Compañía de Seguros Generales S.A. contra la Flota Mercante Grancolombiana, la Sala de Casación Civil de la Corte Suprema de Justicia, con ponencia de José María Esguerra Samper, manifestó:

"Cuando hay reaseguro, se presentan dos contratos diferentes aunque estrechamente vinculados entre sí i el uno es accesorio al otro, por que no se concibe un reaseguro sin un seguro previo o al menos concomitante. Es por ello, que no hay lugar a la subrogación legal que tiene la aseguradora que pague una indemnización. Es claro que el Tribunal no interpretó erróneamente el artículo 1096 C. De Co. al haberlo considerado inaplicable al caso que el reasegurador cumpla con la obligación que le impone el contrato de reaseguro para con el asegurador. Si bien el reasegurador es un tercero en el contrato celebrado entre el asegurador y el asegurado, cuando se produce el siniestro y a consecuencia de ello paga al asegurador lo que según el contrato de reaseguro está obligado a pagarle, está pagando deuda propia, en este caso el reasegurador si está obligado a pagarle, está pagando deuda propia, en este caso el reasegurador si está obligado a pagar la prestación a su cargo derivada del

31 Ibid, p. 193

32 STIGLITZ Rubén. La distorsión del Contrato de Reaseguro. El Fronting. Situación en Argentina. En: Revista Ibero-Latinoamericana de Seguros no. 23, 2005, p. 173. 
contrato de reaseguro y por consiguiente no está satisfaciendo una deuda ajena, aunque para el lo sea la del asegurador para con el asegurado. La consecuencia, el pago hecho por el reasegurador por razón del reaseguro en caso de siniestro, no priva al asegurador del derecho que le otorga el art. 1096 del C.Co. Es apenas natural y consecuencia propia de que a la ley repugne el enriquecimiento sin justa causa, que si el asegurador obtiene el reconocimiento total o parcial de la indemnización que ha tenido que pagar al asegurador por razón de la ocurrencia del siniestro, en una misma proporción, tendrá que hacer el correspondiente reembolso. No en otra forma puede entenderse la expresión del art. 1134 del C.Co. de que el reasegurador comporte la suerte del asegurador.

(...)

La obligación del asegurador para con el asegurado no es distinta a la del reasegurador para con áquel y que ambos tienen su fuente en contratos diferentes. Por consiguiente si el reasegurador paga, no está extinguiendo la obligación a cargo del asegurador, sino la que existe a su propio cargo. Ese pago no extingue, pues, la obligación derivada del contrato de seguro ni lo subroga, como atrás quedó dicho, en los derechos que éste enfrente el responsable del siniestro, como ocurre con la hipótesis prevista en el art. 1096"

\section{CONCLUSIONES}

El fronting es una operación mediante la cual el asegurador cede a un reasegurador la totalidad o casi la totalidad del riesgo inicialmente asumido. Se crea entonces, lo que los ingleses denominan, un "seguro de fachada", expresión que se utiliza para designar a la entidad aseguradora que asume un riesgo pero transfiere la cobertura integra o gran parte de ella a otros reaseguradores.

La legislación colombiana no dispone de ninguna regulación respecto al fronting. El análisis de su operatividad debe realizarse a partir de las normas generales del reaseguro. No obstante, dicha operación no está expresamente prohibida por lo tanto es una práctica legal y frecuente en el mercado reasegurador colombiano.

La clasificación del fronting, en fronting real y fronting falso, expuesto por un sector reducido de la doctrina, a nuestro juicio tiene efectos meramente académicos. En la práctica, los efectos de la operación del fronting se producen sin consideración a la oportunidad que ostente el asegurado de escoger el reasegurador a quien la totalidad o casi la totalidad del riesgo, le fue cedido por el asegurador-cedente. En el evento que el asegurado tenga alguna injerencia en la escogencia del reasegurador, poco importa. Las obligaciones del contrato de seguro se mantienen incólumes y con ello la obligación del asegurador de soportar el detrimento económico que puede representar que el reasegurador no conmine las obligaciones del contrato de reaseguro celebrado.

Los derechos y obligaciones de la parte aseguradora y asegurada no tienen variación alguna por la celebración de un contrato de reaseguro fronting, en 
virtud del cual el asegurador-cedente cedió la totalidad o casi la totalidad del riesgo asumido en virtud del contrato de seguro.

Conforme a la normatividad colombiana, el pacto de cláusulas cut through, pago simultaneo, cooperación y control de reclamos en los contrato de seguro, son nulas de pleno derecho por violar las normas imperativas que regulan dicho contrato.

\section{BIBLIOGRAFÍA}

\section{NORMATIVIDAD}

Código de Comercio: artículos 1134-1136, 1080 y 1744.

Circular Básica Jurídica: Parte II, Título IV, Capítulo II.

Estatuto Orgánico del Sistema Financiero: Parte Primera, Capítulo XI.

Decreto 2272 de 1993

Decreto 2555 de 2010: Capítulos 1, 2 y 3 del Título 1 del Libro 30

\section{JURISPRUDENCIA}

Laudo Arbitral en derecho del 8 de noviembre de 1995. Árbitro: José Humberto Botero. Secretario: Jorge Hernán Gil Echeverry.

Sentencia de la Sala de Casación Civil de la Corte Suprema de Justicia. Proceso de la Libertad Compañía de Seguros Generales S.A. contra la Flota Mercante Grancolombiana, la Sala de Casación Civil de la Corte Suprema de Justicia, MPJosé MaríaEsguerra Samper.

\section{DOCTRINA}

SOBRINO, Waldo, Fronting: un gran peligro para la mayoría de las empresas aseguradas latinoamericanas. Revista Latinoamericana de Seguros, Número 23, Octubre 2005, pp. 184-200.

IGNACIO JARAMILLO, Carlos Ignacio. Distorsión Funcional del Contrato de Reaseguro Tradicional, Bogotá, Editoral: Pontificia Universidad Javeriana, AIDA, p. 352.

STIGLITZ Rubén, Temas de Derecho de Seguros, Bogotá Colombia, Pontificia Universidad Javeriana, Facultad de Ciencias Jurídicas: Grupo Editorial Ibañez, 2010 (Colección Internacional No. 23) pp. 174-181.

NARVAEZ, Bonnet, Jorge Eduardo. El "Fronting" en el reaseguro y la cláusula "cuttbrough". Revista Latinoamericana de Seguros, Número 30, enero - junio 2009, pp. 138-165. 
CANDELARIO, Macías, María Isabel, Apuntes sobre el "fronting": inconvenientes y ventajas. Foro de Derecho Mercantil, Revista Internacional No. 8, Editoral: Legis, Julio-Septiembre 2005, pp. 33-55.

BARROSO DE MELLO, Sergio. Apuntes sobre el fronting en el reaseguro brasilero, 28 de noviembre de 2010, RIS, Número 33, Bogotá.

IGNACIO JARAMILLO CARLOS IGNACIO. El Contrato de Seguro, Bogotá, Pontificia Universidad Javeriana, Editoral Temis, Tomo V, 2013.

CÁMARA DE COMERCIO-ACOLDESE-AIDA. Laudos Arbitrales en Materia de Seguros, Tomos II y IV, 2004. 